\title{
Arranjo Espacial na Creche: Espaços para Interagir, Brincar Isoladamente, Dirigir-se Socialmente e Observar o Outro
}

\author{
Renata Meneghini ${ }^{1}$ \\ Mara Campos-de-Carvalho ${ }^{2}$ \\ Universidade de São Paulo, Ribeirão Preto
}

\begin{abstract}
Resumo
Objetivando comparar a preferência de ocupação por áreas espaciais durante a ocorrência de interação criança-criança, atividade individual, espectador e comportamento socialmente dirigido, analisou-se a distribuição espacial de crianças de 2-3 anos da creche universitária do Campus-USP-Ribeirão Preto(SP). Foram analisados os vídeos coletados em estudo anterior, por 3 câmeras automáticas de videoteipe em 3 fases, todas com pelo menos uma zona circunscrita (ZC): FI-estantes com superfície de apoio delimitando uma ZC e duas áreas sem circunscrição (5 sessões); FII-2 ZC, com e sem superfície de apoio (5 sessões); FIII-3 ZC , duas da fase anterior e uma cabana (4 sessões). A análise por minuto das localizações infantis evidenciou que espectador ocorreu preferencialmente na área ao redor do adulto (diferença significativa nas Fases I e II) e as demais categorias ocorreram preferencialmente na ZC com apoio, havendo redução significativa de interações na área do adulto na FIII.

Palavras-chave: Psicologia ambiental; organização espacial; interação infantil; creche; abordagem ecológica.
\end{abstract}

Spatial Arrangement in a Day Care Center: Spaces for Peer Interaction, Playing Alone, Socially Directing Behavior and Observing Others

\begin{abstract}
The preferential use of spatial areas by 2- to 3-year-old children from a Brazilian university day care center was compared for 4 classes of behavior: peer interaction, isolated activity, spectator and socially directed behavior. Videos from a preceding study using three automatic video cameras in three phases $(\mathrm{Ph})$, each of them with at least one circumscribed zone (ZC), were analyzed: PhI-shelves with surface of support delimiting one $\mathrm{CZ}$ and two areas without circumscription (5 sessions); $\mathrm{PhII}-2$ $\mathrm{CZ}_{\mathrm{s}}$, one with and another without surface of support (5 sessions); PhIII-3 CZ, two of the preceding phase and a cardboard doll house (4 sessions). The minute by minute analysis of the children positions showed the preferential occurrence of spectators in the area around the adult (significant difference among areas in Phases I and II); the other three behaviors occurred mainly in the $\mathrm{CZ}$ with support, and there was a significant decrease in peer interactions in the area around the adult in PhIII. Keywords: Environmental psychology; spatial organization; peer interaction; day care center; ecological approach.
\end{abstract}

Uma abordagem ou perspectiva ecológica, que enfatiza a relação bidirecional entre pessoa e ambiente, tem sido apontada como necessária para o estudo do desenvolvimento humano (Bronfenbrenner, 1977, 1979, 1993, 1995; Campos-de-Carvalho, 1993; Moore, 1987; Stokols, 1978, 1995; Tudge, Gray \& Hogan, 1997; Valsiner, 1987; Wohlwill \& Heft, 1987). Esta perspectiva aponta o papel ativo da pessoa em seu desenvolvimento, através de suas capacidades para descobrir, manter e/ou alterar as propriedades do ambiente.

Os comportamentos infantis são influenciados pelo ambiente físico e social, fornecido pelos adultos, que os organizam de acordo com seus objetivos pessoais, construídos com base em suas expectativas sócio-culturais

\footnotetext{
${ }^{1}$ Parte da dissertação de Mestrado da $1^{\mathrm{a}}$ autora, sob orientação da segunda. Nossos agradecimentos à FAPESP e ao CNPq pelos auxílios recebidos e ao Prof. Dr. Carlos Roberto Padovani (Depto. de Bioestatística/Unesp, Campus de Botucatu), pela análise estatística.

${ }^{2}$ Endereço para correspondência: Faculdade de Filosofia, Ciências e Letras de Ribeirão Preto, USP. Av. dos Bandeirantes, 3900, 14040 901, Ribeirão Preto, SP. Fone: (16) 6023661 / Fax:6335668.E-mail:mara@ffclrp.usp.br
}

sobre os comportamentos e desenvolvimento infantis. Por outro lado, a criança participa ativamente de seu desenvolvimento através de suas relações com o ambiente físico e social, dentro de um contexto sócio-histórico específico. A criança explora, descobre e inicia ações em seu ambiente; seleciona parceiros, objetos e áreas para suas atividades, mudando o ambiente através de seus comportamentos.

Diferentes maneiras de organizar o espaço oferecem suporte para diversas formas de organização social, especialmente em ambientes de educação coletiva, tais como em creches, onde um adulto cuida simultaneamente de várias crianças, sendo que os parceiros mais disponíveis para interação são outras crianças, geralmente coetâneos. As interações entre crianças são tão importantes quanto as interações adulto-criança para o desenvolvimento infantil, ambas servindo a diferentes funções e exigindo competências diversas das crianças (Hartup, 1987; Oliveira \& Rossetti Ferreira, 1993).

A importância de aspectos físicos do ambiente para as interações infantis tem sido demonstrada (Ex.: Read, Sugawara 
\& Brandt, 1999; Weinstein \& David, 1987; Wohlwill \& Heft, 1987), especialmente quanto ao papel dos objetos (Ex.: Eckerman \& Stein, 1982; Mueller \& Lucas, 1975; Mello \& Sperb, 1997; Nadel \& Baudonnière, 1981; Stambak \& Verba, 1986). Porém, poucos estudos têm investigado a influência nos comportamentos infantis de espaços abertos e fechados, referentes à ausência ou presença de barreiras na área de atividades, particularmente em creches, tais como os estudos de Legendre (Legendre, 1986; Legendre \& Fontaine, 1991) e Moore (1987), que examinam a variável física denominada por Legendre de arranjo espacial - maneira como móveis e equipamentos existentes em um local estão posicionados entre si.

Os três tipos de arranjos espaciais, descritos por Legendre em seus estudos com crianças de 2-3 anos em creches francesas (Legendre, 1986, 1989, 1999; Legendre \& Fontaine, 1991), são os seguintes: 1) arranjo visualmente aberto (também denominado de arranjo semi-aberto, em seus estudos iniciais) - proporciona à criança uma visão de todo o local, sendo caracterizado pela presença de zonas circunscritas - áreas delimitadas, pelo menos em três lados, por barreiras formadas por mobiliários, parede, desnível do solo, etc.; é necessário o uso de barreiras baixas o suficiente para que as crianças visualizem facilmente o adulto, devido ao comportamento de apego, típico dessa faixa etária (Rossetti Ferreira, 1984); 2) arranjo aberto - caracterizado pela ausência de zonas circunscritas, geralmente havendo um espaço central vazio; 3 ) arranjo visualmente restrito (denominação anterior: arranjo fechado) - barreiras físicas, por exemplo um móvel alto, dividem o ambiente em duas ou mais áreas, impedindo uma visão total do local pelas crianças. No arranjo com zonas circunscritas, as crianças as ocupam preferencialmente, nas quais ocorrem interações afiliativas entre elas. Já nos outros dois tipos de arranjos, as crianças tendem a permanecer em volta do adulto, porém ocorrendo pouca interação com o mesmo e entre crianças.

O contexto pouco estruturado de nossas creches, especialmente as que atendem população de baixa renda tal como número grande de crianças pequenas (Ex.: 10 a 35 crianças entre 18 a 36 meses) sob a supervisão de um só adulto; escassez de mobiliário, objetos e equipamentos; ausência de zonas circunscritas - não favorece interações, seja entre criança-educador e, especialmente, entre crianças menores de 3 anos, cujas habilidades verbais e sociais estão se desenvolvendo.

Nossos estudos direcionam-se para a contribuição do arranjo espacial para a oportunidade de interações de coetâneos, tanto entre si como com a educadora, analisando a ocupação do espaço por grupos de crianças em creches, utilizando a metodologia denominada por Bronfenbrenner (1977, 1979) de experimento ecológico. Esta metodologia propõe a realização de manipulações sistemáticas de uma única variável, a que está sob investigação - em nossos estudos, o arranjo espacial -, mantendo-se os demais componentes ambientais presentes, ou seja, aquelas manipulações ocorrem no interior do sistema ecológico, preservando-se, tanto quanto possível, o sistema de interdependência entre os componentes ambientais.

Nossos estudos, inicialmente com crianças de 2-3 anos de creches filantrópicas e na creche do Campus da USP de Ribeirão Preto (Campos-de-Carvalho, Meneghini \& Mingorance, 1996; Campos-de-Carvalho \& Mingorance, 1999; Campos-de-Carvalho \& Padovani, 2000; Camposde-Carvalho \& Rossetti Ferreira, 1993; Meneghini \& Campos-de-Carvalho, 1997) e atualmente com crianças de 1-2 e 3-4 anos de creches municipais de Ribeirão Preto (Bonfim, 2002), têm apontado o papel de suporte do arranjo espacial para a ocorrência de interações entre crianças e delas com a educadora, evidenciado pelos seguintes resultados: 1) papel mais forte do adulto no arranjo com menor estruturação espacial (em locais sem presença de zonas circunscritas, onde o adulto é o único elemento estruturador do ambiente, ou em locais com presença de somente uma zona circunscrita), especialmente para as crianças que se associavam menos com outras, para as quais a proximidade da educadora foi mais necessária; 2) em arranjos com maior estruturação espacial - presença de pelo menos duas zonas circunscritas -, estas foram as áreas mais ocupadas, havendo acréscimo no número de agrupamentos entre crianças (sejam agrupamentos preferenciais ou não), especialmente aqueles com maior número de componentes, e diminuição de agrupamentos com o adulto; 3) as crianças de 3-4 anos apresentaram o mesmo padrão de distribuição espacial das crianças de 2-3 anos; já as de 1-2 anos apresentaram um padrão diferente quando na presença de arranjo com zonas circunscritas, pois ocuparam com freqüência semelhante estas zonas e a área ao redor do adulto, indicando que crianças menores necessitam mais da proximidade da educadora que as mais velhas, em qualquer tipo de arranjo espacial.

No presente trabalho, utilizou-se a coleta de dados do estudo de Campos-de-Carvalho e Mingorance (1999), o qual foi proposto para responder questões sobre o papel das variáveis circunscrição e superfície de apoio (presente nas estantes utilizadas para delimitar as zonas circunscritas), para a ocupação preferencial da zona circunscrita (ZC). Os dados foram coletados durante atividades livres de um grupo de crianças de 2-3 anos da creche do Campus da USP de Ribeirão Preto, por três câmeras automáticas de videoteipe em três fases: I - foco na circunscrição - estantes com superfície de apoio delimitando uma ZC e duas áreas sem circunscrição (5 sessões); II - foco na superfície de apoio $2 \mathrm{ZC}_{\mathrm{s}}$, com e sem superfície de apoio (5 sessões); III - 3 
$\mathrm{ZC}_{\mathrm{s}}$, duas da fase anterior e uma cabana (4 sessões). Os dados evidenciaram ocupação preferencial da ZC com apoio e, com o aumento do número de $\mathrm{ZC}_{\mathrm{s}}$, houve um decréscimo significativo na ocupação da zona do adulto e maior ocupação das $Z_{\mathrm{s}}$.

Nosso interesse, no presente estudo, foi investigar a relação entre arranjo espacial e a ocorrência de quatro categorias interacionais em um grupo de crianças de 2-3 anos em creche. Para tanto, procedemos a uma nova análise das fitas de vídeos coletadas no estudo de Campos-deCarvalho e Mingorance (1999). Especificamente, o objetivo do presente estudo foi comparar, intra e inter-fases, a ocorrência de interação, atividade individual, espectador e comportamento socialmente dirigido, verificando a preferência de ocupação, pelas crianças, por áreas específicas.

Estas quatro categorias comportamentais (vide definições na seção de Análise de Dados) foram elaboradas com base nos estudos de Branco, Carvalho, Pedrosa e Gil (1989), Carvalho (1992), Legendre e Fontaine (1991) e de Rubiano e Rossetti-Ferreira (1995), nos quais há uma convergência na conceituação de interação, quanto à ocorrência de direcionamento social com ações recíprocas entre crianças com idade inferior a 4 anos. As quatro categorias elaboradas no presente trabalho são interacionais, desde que sua análise foi feita em um contexto de um grupo de crianças brincando, contexto este visto como um sistema dinâmico, ou seja, como um campo social de interações, com possibilidade contínua de regulação, recíproca ou não, entre as crianças. Desta maneira, as "ações individuais não são estranhas ou alheias ao campo social, que sempre as constitui." (Carvalho, Império-Hamburguer \& Pedrosa, 1999, p. 208). Portanto, uma atividade individual não se opõe à interação social, podendo ser um momento desta (Pedrosa \& Carvalho, 1995).

\section{Método}

\section{Participantes}

Foram observadas 14 crianças ( 6 meninas e 8 meninos) e 2 educadoras da creche do Campus da USP em Ribeirão Preto, SP. As crianças faziam parte de um grupo da creche subdividido em dois, cada um composto por 7 crianças e 1 educadora, os quais desenvolviam várias atividades em conjunto. No início do estudo, a idade média das crianças era de 27 meses (22-31 meses), as quais já estavam familiarizadas com as educadoras e entre si, pois freqüentavam a creche há 2 anos, com exceção de uma criança que havia ingressado há 1 ano.

A creche atende filhos de funcionários, alunos e docentes, de 3 meses a 6 anos e 11 meses, sendo considerada uma creche modelo, devido ao padrão de alta qualidade do atendimento, tal como: busca constante das condições favoráveis ao desenvolvimento global das crianças; boas instalações, em termos tanto de equipamentos, materiais, mobiliários e decorações, como de espaços internos e externos, com ampla área verde; formação continuada dos profissionais; razão adulto-criança adequada (Ex.: um adulto para sete crianças para o grupo de 2-3 anos), tendo as educadoras 6 horas diárias de trabalho; preocupação com a integração creche-família; programação educacional adequada às necessidades infantis, desde a organização do espaço físico até a elaboração e execução de atividades diversas, onde o brincar está presente em todos os momentos.

\section{Local e Situação}

A coleta de dados foi realizada no período da manhã, em horário rotineiro para ocorrência de atividades livres (atividades infantis com pouca ou nenhuma interferência do adulto), em uma sala de $35 \mathrm{~m}^{2}$, utilizada habitualmente pelo grupo, decorada com móbiles e painéis de pinturas nas paredes, com personagens de contos infantis. Também havia um armário de madeira, permanentemente trancado e encostado numa parede. Os materiais, pertencentes à creche e de utilização diária, eram colocados no centro da sala antes do início de cada sessão, consistindo de brinquedos seminovos, como bolas, carrinhos, brinquedos de encaixe, livrinhos de pano, almofadas pequenas, revistas, etc.

\section{Equipamentos e Técnica de Coleta de Dados}

A coleta foi feita por três câmeras de videoteipe com funcionamento simultâneo e sem a presença do operador, ligadas segundos antes da entrada das crianças na sala. Estas câmeras, cobertas por panos com abertura para as lentes, eram fixadas em suportes de madeira presos em três paredes, de modo que cada uma focalizava uma área da sala, abrangendo quase todo o local, havendo cerca de $2 \mathrm{~m}^{2}$ fora dos focos. Nos períodos entre as sessões, os suportes de madeira permaneciam encobertos pelos panos.

Para a estruturação do espaço foram utilizadas: oito estantes de madeira com superfície de apoio $(1,00$ X $0,30 \mathrm{X}$ $0,50 \mathrm{~m})$, vazadas na parte posterior e contendo uma prateleira na parte inferior; quatro divisórias de madeira, tipo grade $(1,00 \times 0,02 \times 0,50 \mathrm{~m})$; um caixote de papelão resistente e colorido $(0,92 \times 0,80 \times 0,76 \mathrm{~m})$, pertencente à creche $\mathrm{e}$ habitualmente utilizado pelas crianças como cabana, pois possuía aberturas nas quatro laterais caracterizando janelas e portas, sendo seu fundo o teto da cabana.

\section{Procedimento}

Foram realizadas três fases, cada uma com estruturação espacial específica, porém caracterizando um arranjo espacial 


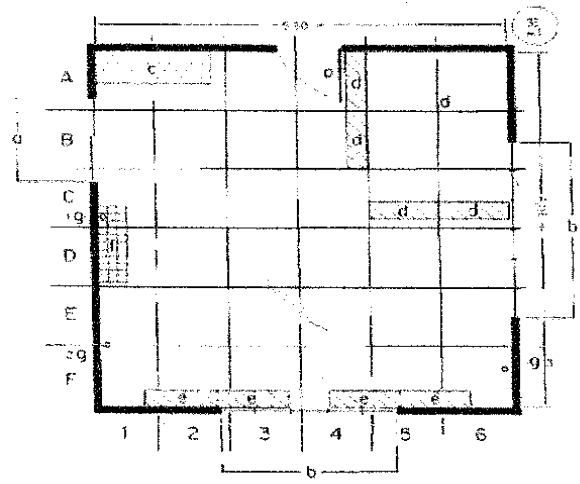

FASE I
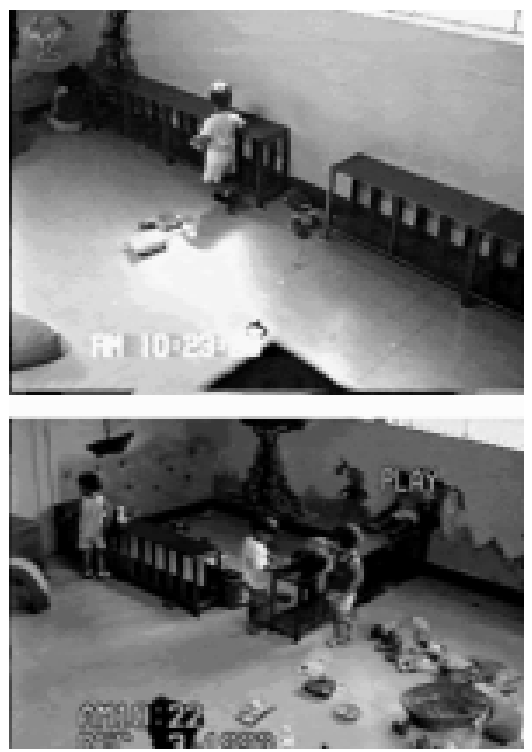

FASE II
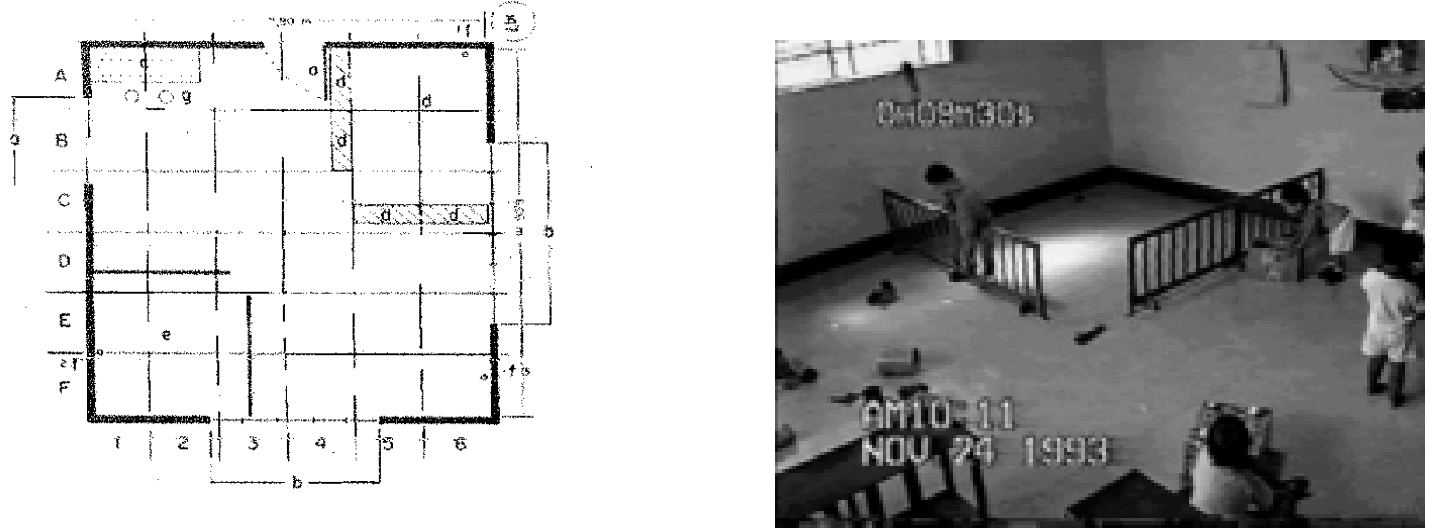

FASE III
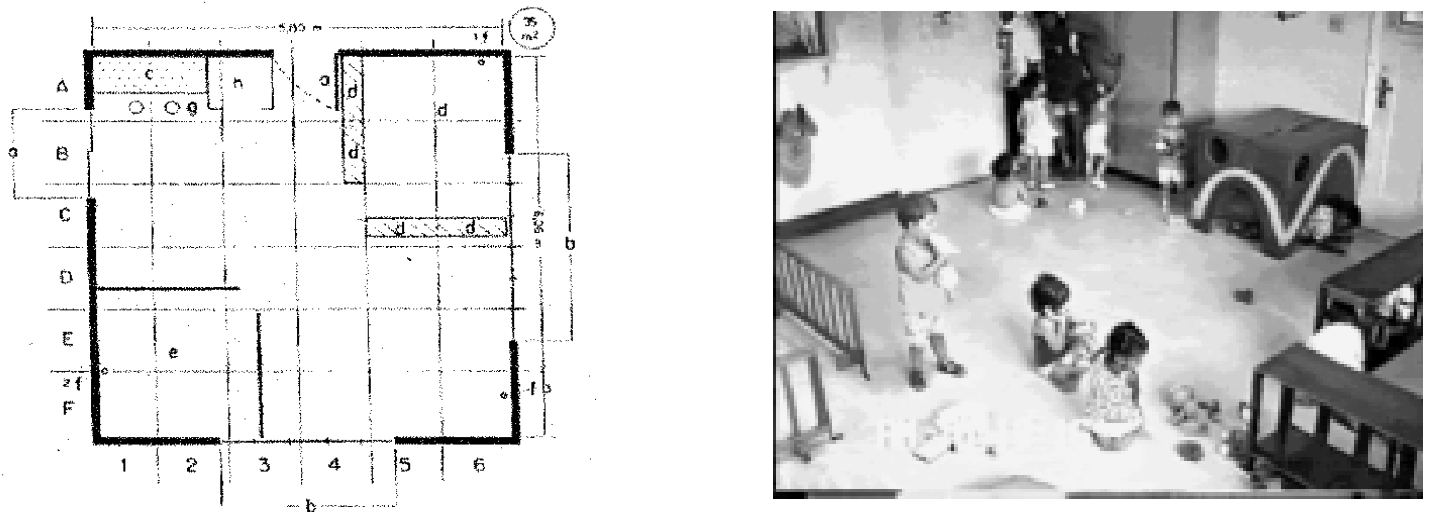

Figura 1. Arranjo espacial da sala em cada fase ( $a$ indica portas; $b$, vitrôs; $c$, armário; $d$, zona circunscrita com apoio; $e$, zonas espaciais sem circunscrição na Fase I e zona circunscrita sem apoio nas Fases II/III; $f$, g, zona do adulto, respectivamente na Fase I e nas Fases II/III; h, cabana na Fase III). 
semi-aberto. A Figura 1 ilustra o arranjo espacial, mostrando uma planta quadriculada e fotos da sala em cada fase.

A duração média das sessões era de 30 minutos $(25$ a 45 minutos), sendo seu início e término decididos pelas educadoras; foram desconsiderados os primeiros minutos de cada sessão, para permitir a entrada na sala de pelo menos metade do grupo, sendo analisados cerca de 27 minutos por sessão.

Foi proposto às educadoras que, sempre que possível, permanecessem em seu local habitual na sala, mas que, se necessário, uma delas poderia sair momentaneamente, ficando o grupo apenas com uma educadora, o que já era habitual ocorrer na creche. Foram necessárias instruções às educadoras para que atendessem as solicitações das crianças, porém não direcionassem suas atividades, pois, durante a primeira sessão, elas propuseram e participaram de atividades. Também foi solicitado que o grupo de crianças utilizasse diariamente o local estruturado com as estantes, para a ocorrência de atividades livres.

Fase I-Zonas espaciais com e sem circunscrição.

Utilizando quatro estantes com superfície de apoio (30 cm de largura), montou-se uma zona circunscrita delimitada em quatro lados, contendo uma abertura para a passagem de crianças. Dois lados foram delimitados pela quina de duas paredes e os outros dois pelas estantes, sendo as duas estantes de cada lado ligadas por braçadeiras de metal e aquela próxima à parede foi fixada nesta por braçadeiras de metal, para evitar o deslocamento das estantes. Outras quatro estantes semelhantes foram encostadas linearmente contra uma parede, sem formar circunscrição, estruturando duas zonas espaciais, cada uma formada por duas estantes ligadas entre si e fixadas no chão por braçadeiras de metal.

Além das zonas espaciais estruturadas na sala, havia a zona do adulto - área em torno de um metro ao redor do local de permanência habitual das educadoras. Neste local foi colocado um colchonete para as educadoras se sentarem.

Após um período de 8 dias úteis para familiarização do grupo ao novo arranjo espacial da sala (não interesse em observar reação à novidade), foram realizadas cinco sessões de coleta de dados em 2 semanas consecutivas.

\section{Fase II: Zona circunscrita com e sem superficie de apoio.}

A coleta de dados desta fase iniciou-se 12 dias após o término da fase anterior. A zona circunscrita com superfície de apoio da Fase I permaneceu na sala e houve a montagem de outra zona circunscrita, aproveitando a quina de duas paredes para estruturar dois lados; quatro divisórias sem superfície de apoio (2 cm de largura) delimitaram os outros dois lados (duas divisórias de cada lado eram ligadas entre si e à parede por braçadeiras de metal), havendo uma abertura para a passagem das crianças. Estas duas zonas circunscritas, com cerca de $6 \mathrm{~m}^{2}$ de superfície, eram eqüidistantes da zona do adulto. A zona do adulto foi deslocada para outra área da sala, dada a estruturação da segunda zona circunscrita, havendo substituição do colchonete da Fase I por duas almofadas pequenas.

Após 5 dias úteis de familiarização do grupo à nova estruturação do espaço, foram realizadas cinco sessões de coleta de dados em 2 semanas consecutivas.

Fase III: Introdução da cabana.

A estruturação espacial da fase anterior foi mantida, havendo a introdução do caixote de papelão colorido, tipo cabana, constituindo uma terceira zona circunscrita. Esta possuía aberturas nas quatro laterais caracterizando janelas e portas, de tal modo que, quando dentro, a criança podia visualizar toda a sala, condição essencial para um arranjo espacial semi-aberto. A cabana era colocada entre a zona do adulto e a zona circunscrita com apoio (devido ao posicionamento das câmeras, ficando no foco da câmera direcionada à zona do adulto); contudo, por ser leve e não fixa ao chão, era facilmente deslocada pelas crianças para qualquer área da sala.

Desde que as crianças já estavam familiarizadas com a estruturação espacial da fase anterior e com a cabana, não houve período de familiarização. A coleta de dados iniciou-se no dia posterior ao término da segunda fase, sendo realizadas quatro sessões em 1 semana.

\section{Análise de Dados}

O procedimento utilizado para o levantamento das posições espaciais das crianças e das educadoras na sala, teve por base a técnica de mapeamento comportamental. Esta técnica vem sendo muito utilizada, especialmente na Psicologia Ambiental, para situar comportamentos específicos dentro de um ambiente, registrando sistematicamente localizações e atividades dos usuários, permitindo verificar em que extensão indivíduos diferentes usam o mesmo espaço de modos diferentes (Elali, 1997; Ledingham \& Chappus, 1986; Proshansky, Ittelson \& Rivlin, 1970; B. Sommer \& R. Sommer, 1997).

Para auxiliar na identificação da localização das crianças no monitor de TV, foi utilizada uma planta quadriculada da sala, desenhada numa folha de papel, onde cada quadrado correspondia a $1 \mathrm{~m}^{2}$ de área, sendo identificado por sua abscissa e ordenada, marcadas por letras e números, respectivamente. A cada minuto, congelava-se a imagem e localizava-se uma criança por vez na tela do monitor, sendo sua localização transposta para a planta quadriculada, auxiliando na verificação de que área específica ela se encontrava; analisava-se também suas ações, correndo a fita 
de vídeo para antes e depois do minuto analisado (no mínimo 3 segundos), para apreensão do desenrolar das ações infantis. Foi escolhida uma amostragem de tempo com intervalos de 1 minuto, com base no estudo de Ormos, Rubiano e Rossetti Ferreira (1993), no qual comparou-se dados obtidos com amostragens de 15, 30 e 60 segundos. A constatação de padrões semelhantes de distribuição espacial de crianças de 2-3 anos nos três intervalos, possibilita o uso da amostragem de tempo de 1 minuto sem perda da acuracidade da observação e com economia do tempo de análise, o que é recomendável do ponto de vista da parcimônia científica.

Para cada criança havia uma folha de registro, na qual se anotava, a cada minuto, o que ela estava fazendo, onde, com quem e com que objeto, o que então permitia categorizar sua ação de acordo com quatro categorias comportamentais pré-definidas. As seguintes categorias, excludentes entre si, foram elaboradas com base nos estudos de Branco e colaboradores (1989), Carvalho (1992), Legendre e Fontaine (1991) e Rubiano e RossettiFerreira (1995):

1) Interação - duas ou mais crianças direcionadas entre si e compartilhando atividade, com ações mútuas e/ou complementares. Exemplos de atividades compartilhadas: a) dois meninos empurrando carrinho, cada um com o seu; um deles para de empurrar, olha para o outro que está atrás e empurra seu carrinho para trás; o outro continua empurrando para frente; ambos se olham e trombam os carrinhos, rindo; em seguida repetem a brincadeira; b) uma criança se aproxima de outra, olham-se, uma entrega um carrinho, a outra pega, fala algo e sai de perto. Ao registrar, diferenciava-se as interações entre crianças daquelas com a presença da(s) educadora(s), porém apenas foram computadas neste trabalho as ocorrências entre crianças;

2) Comportamento socialmente dirigido - a criança olha para o outro, adulto ou criança(s), e concomitante ou imediatamente antes ou após, emite um outro comportamento - verbaliza, toca, sorri, oferece ou aceita algo, bate, chora, etc. (Legendre \& Fontaine, 1991; Mueller \& Lucas, 1975) -, sem ocorrência de resposta do outro durante um intervalo de, no mínimo, 6 segundos. Foram computadas as ocorrências entre crianças exclusivamente, apesar de sempre ser registrado o alvo deste comportamento;

3) Espectador - a criança observa atentamente outra(s) criança(s) e/ou adulto(s) ou uma situação. O registro não diferenciava o alvo da observação, pois quase sempre era impossível definir precisa e especificamente a direção do olhar da criança;

4) Atividade individual - criança ocupada em atividade consigo própria, seja utilizando objetos ou explorando partes do próprio corpo.
No caso onde no mesmo intervalo de tempo ocorria mais de uma destas categorias, para cada intervalo de tempo registrava-se, com base em Carvalho (1992, p. 74), "a ocorrência da categoria hierarquicamente mais elevada", ou seja aquela com maior envolvimento social (de interação, maior envolvimento social, para atividade individual, com menor); considerava-se também aquela categoria mais próxima ao minuto analisado. Entretanto, é necessário apontar que todas as categorias são, por princípio, interacionais, desde que a análise foi feita em um contexto de grupo de crianças brincando, no qual há a possibilidade contínua de regulação, sendo ou não recíproca; desta maneira, uma atividade individual, portanto, não se opõe à interação social, podendo ser um momento desta (Pedrosa \& Carvalho, 1995).

Com base nos registros das sessões, em cada área específica obteve-se para cada criança e então para o grupo: 1) freqüência de ocorrência de cada categoria comportamental; 2) freqüência média de ocorrência de cada categoria (por criança: somatória da freqüência nas sessões de cada fase, dividido pelo número de sessões em que esteve presente; para o grupo todo: somatória da freqüência média de cada criança dividida pelo número de crianças). Utilizou-se a análise de variância da prova de Friedman, na comparação intra-fase da ocorrência das categorias e também para comparações inter-fases dessas categorias em cada área específica. Todas as discussões estatísticas foram feitas no nível de significância $p<0,05$.

\section{Resultados}

Os dados apresentados referem-se ao conjunto das sessões de cada fase (as mesmas tendências foram observadas na maioria delas) e para o grupo de crianças. A Tabela 1 permite uma comparação da preferência por determinadas áreas da sala pelo grupo de crianças, para a ocorrência de cada uma das quatro categorias comportamentais.

Atividade individual ocorreu preferencialmente na zona circunscrita com apoio (ZC com apoio) nas três fases, porém com significância apenas na Fase III $\left(\chi^{2}=18,39, p<0,0000006\right.$; ZC com apoio: $p \leq 0,034)$. Na Fase I salientou-se também a zona do adulto (ZA) e zonas sem circunscrição, porém não havendo diferença significativa entre as áreas $\left(\chi^{2}=5,15\right.$, $p>0,05)$; a zona do adulto foi a área preterida para sua ocorrência nas Fases II e III, sendo significativamente inferior na terceira $\left(\chi^{2}=18,39, p<0,0000006\right.$; ZA: $\left.p \leq 0,034\right)$.

O comportamento de espectador ocorreu preferencial e significativamente na zona do adulto na Fase I $\left(\chi^{2}=19,32\right.$, $p<0,0000006$; ZA: $p \leq 0,042)$ e na Fase II $\left(\chi^{2}=23,09\right.$, 
Tabela 1

Freqüência Média de Ocorrência de Atividade Individual, Espectador, Interação e Comportamento Socialmente Dirigido (CSD)

\begin{tabular}{lccccc}
\hline & Individual & Espectador & Interação & CSD & Total \\
\hline \multicolumn{1}{c}{ Fase I } & & & & & \\
Zona do adulto & 35 & 46 & 20 & 2 & 103 \\
Zona circunscrita com apoio & 32 & 10 & 23 & 2 & 67 \\
Zonas sem circunscrição & 31 & 10 & 12 & 1 & 54 \\
Resto da sala & 24 & 6 & 3 & 0,2 & 33,2 \\
\hline Total & 122 & 72 & 58 & 5,2 & 257,2 \\
\hline$\quad$ Fase II & & & & & \\
Zona do adulto & 19 & 31 & 25 & 2 & 77 \\
Zona circunscrita com apoio & 38 & 27 & 46 & 2 & 113 \\
Zona circunscrita sem apoio & 21 & 7 & 11 & 1 & 40 \\
Resto da sala & 30 & 8 & 12 & 1 & 51 \\
\hline Total & 108 & 73 & 94 & 6 & 281 \\
\hline$\quad$ & & & & \\
Fase III & 8 & & & 2 & 32 \\
Zona do adulto & 34 & 19 & 28 & 8 & 89 \\
Zona circunscrita com apoio & 19 & 14 & 16 & 3 & 52 \\
Cabana & 16 & 25 & 20 & 2 & 63 \\
Resto da sala & 14 & 3 & 2 & 0,3 & 19,3 \\
\hline Total & 91 & 81 & 68 & 15,3 & 255,3 \\
\hline
\end{tabular}

$p<0,0000006$; ZA: $p \leq 0,042)$; nesta segunda fase também foi significativamente mais elevada na zona circunscrita com apoio $(p \leq 0,042)$. Na terceira fase, sua ocorrência foi significativamente mais elevada na cabana $\left(\chi^{2}=20,52\right.$, $p<0,0000006$; cabana: $p \leq 0,034)$.

Nas três fases, interação ocorreu preferencial e significativamente na zona circunscrita com apoio (Fase I: $\chi^{2}=18,06, p<0,0000006$; ZC com apoio: $p \leq 0,042 /$ Fase II: $\chi^{2}=17,34, p<0,000011 ; Z C$ com apoio: $p \leq 0,042$ / Fase III: $\chi^{2}=14,54, p<0,000097 ; Z C$ com apoio: $\left.p \leq 0,034\right)$. Além da zona circunscrita com apoio, as interações entre crianças também ocorreram significativamente, na Fase I, na zona do adulto $(p \leq 0,042)$ e na Fase III também nas duas outras zonas circunscritas (ZC sem apoio e cabana: $p \leq 0,034)$.

Comportamento socialmente dirigido, apesar de sua baixa freqüência em todas as fases, quando ocorreu, foi preferencialmente na zona circunscrita com apoio nas três fases, porém com diferença significativa entre as áreas somente na Fase III $\left(\chi^{2}=20,69, p<0,0000006\right.$; $Z \mathrm{C}$ com apoio: $p \leq 0,034)$; além dessa área, destacou-se também a zona do adulto nas Fases I e II, porém sem diferença significativa entre áreas.

Foi realizada uma análise comparativa inter-fases, quanto à ocorrência de cada categoria na zona do adulto e na zona circunscrita com apoio, as únicas duas áreas presentes nas três fases. Na zona do adulto, houve diferença significativa entre as fases quanto à ocorrência de: 1) atividade individual $\left(\chi^{2}=14,37, p=0\right)$, sendo sua ocorrência significativamente maior na Fase I ( $p \leq 0,038)$; 2$)$ espectador $\left(\chi^{2}=10,26, p<0,005\right)$, sendo significativamente maior sua ocorrência na zona do adulto nas Fases I e II $(p \leq 0,038)$; 3$)$ interação $\left(\chi^{2}=15,57\right.$, $p=0)$, sendo sua freqüência significativamente maior na zona do adulto nas Fases I e II $(p \leq 0,038)$. É interessante notar que estes três comportamentos nunca ocorreram com freqüência significativamente mais elevada na zona do adulto na Fase III. Quanto ao comportamento socialmente dirigido, ocorreu com freqüência semelhante nesta área nas três fases $\left(\chi^{2}=0,17, p>0,05\right)$.

Em relação à zona circunscrita com apoio, houve diferença significativa entre fases na ocorrência de: 1) espectador $\left(\chi^{2}=7,69, p<0,025\right)$, com maior ocorrência nas Fases II e III $(p \leq 0,038)$; 2$)$ interação $\left(\chi^{2}=8,71, p<0,016\right)$, sendo sua freqüência naquela zona significativamente maior na Fase II $(p \leq 0,038) ; 3)$ comportamento socialmente dirigido $\chi^{2}=9,33$, $p<0,012)$, com maior ocorrência significativa na Fase III $(\phi \leq 0,038)$. Atividade individual foi a única categoria que se manteve constante de uma fase para outra, na comparação de suas ocorrências na zona circunscrita com apoio, sem diferença significativa $\left(\chi^{2}=2,29, p>0,05\right)$. 
Considerando o total de ocorrências das categorias comportamentais a cada fase, independentemente de áreas, a Tabela 1 evidencia que: 1) espectador e comportamento socialmente dirigido ocorreram mais freqüentemente na Fase III; 2) atividade individual diminuiu gradualmente da primeira para a última fase; 3) interação ocorreu com maior freqüência na Fase II, porém sua ocorrência na Fase III foi maior que na primeira fase.

Foi realizado um teste de acordo entre a categorização feita pela primeira autora deste estudo e por uma observadora independente (membro do grupo de pesquisa com experiência de observação de comportamento, mas não com as categorias do presente estudo). Houve uma apresentação oral e escrita das definições das categorias comportamentais utilizadas, exemplificando cada uma delas; com este material em mãos, e também com as folhas de registro, a observadora analisou a terceira sessão de cada fase. $\mathrm{O}$ acordo, considerando as três fases em conjunto, foi de 63\% (66\% na Fase I, 68\% na Fase II e 56\% na Fase III).

Um segundo teste de acordo foi realizado, considerando dois momentos de categorização pela primeira autora deste estudo. Esta analisou novamente a quarta sessão de cada fase, após o término da análise de dados do presente trabalho; esta categorização foi comparada com a realizada no início do estudo. Obteve-se, nas Fases I e II, 80\% de acordo entre estes dois momentos e um acordo um pouco menor na Fase III (72\%).

\section{Discussão}

Este estudo focalizou a relação entre arranjo espacial semi-aberto - variável manipulada - e freqüência de ocorrência de quatro categorias comportamentais no grupo de crianças observadas. De acordo com a metodologia do experimento ecológico (Bronfenbrenner, 1977, 1979; Campos-de-Carvalho, 1993), na coleta de dados mantevese constante, tanto quanto possível, outras variáveis já existentes no ambiente, para preservar a interdependência entre os vários componentes ambientais (Ex.: familiaridade entre os componentes do grupo, presença constante de pelo menos uma educadora na sala, sala e materiais habituais às crianças, horário rotineiro de atividades livres, coleta de dados sem a presença do operador, etc.).

Considerando ainda um controle metodológico, para verificar a precisão do sistema observacional (Dessen \& Murta, 1997; B. Sommer \& R. Sommer, 1997) foram realizados dois testes de acordo, a partir da categorização dos comportamentos observados no vídeo. No primeiro teste, obteve-se um acordo relativamente baixo $(63 \%)$ entre dois observadores independentes, cuja análise posterior dos desacordos permitiu levantar os seguintes motivos: 1) o fato de se considerar, no mínimo 3 segundos antes e depois ao minuto analisado, gerou desacordos quando ocorria mais de uma categoria no mesmo minuto, apesar da instrução dada para se registrar aquela com maior envolvimento social e mais próxima ao minuto analisado; 2) apesar da segunda observadora possuir experiência na observação de comportamento, não possuia treinamento suficiente com análise de vídeo, enquanto que a primeira autora já havia participado de todas as etapas do trabalho, desde a coleta de dados, até a elaboração das definições de categorias e análise de dados.

O segundo teste de acordo evidenciou que, em dois momentos de categorização no decorrer de quase dois anos (desde o início até o término da análise dos dados), a primeira autora preservou seu critério de categorizar os quatro comportamentos infantis, pois obteve-se um índice de acordo considerado satisfatório (Weiner, 1991), um pouco mais elevado nas duas fases iniciais $(80 \%)$. Analisando os desacordos ocorridos na última fase, verificou-se sua concentração nos momentos em que não era possível observar com precisão o que ocorria dentro da cabana, apesar de ter aberturas nas quatro laterais caracterizando portas e janelas (o que permitia à criança, quando dentro, uma visão de toda sala, aspecto essencial na caracterização de um arranjo espacial semi-aberto). Em 17 dos 63 minutos em que a cabana foi ocupada no total das quatro sessões, era possível registrar com precisão quem entrava e quem saía da cabana, mas não as atividades infantis; nos 46 minutos restantes, foi possível analisar o que ocorria dentro da cabana, pois sua abertura inferior ficou na lateral e voltada para a câmera (posição colocada pelas crianças). No segundo momento de análise, houve registro mais freqüente de comportamento não identificado do que no primeiro momento de categorização - provavelmente, ocorreu uma mudança no olhar da pesquisadora, advinda do próprio treinamento continuado em pesquisa, visando a uma observação precisa e confiável, evitando inferências.

No contexto ambiental do presente estudo, com áreas espaciais delimitadas e contendo objetos variados e similares, observou-se o papel ativo destas crianças pequenas, já familiarizadas entre si, para iniciar e manter brincadeiras duradouras sem a mediação direta do educador. Por exemplo, citamos a brincadeira de "trenzinho" que ocorreu na área das zonas sem circunscrição, presente somente na fase inicial. Esta brincadeira, que ocorreu durante 24 dos 38 minutos da última sessão entre dois meninos e uma menina, que enfileiraram no chão três caixas de papelão, utilizadas para trazer os materiais para a sessão; havia alternância da criança que se sentava dentro da primeira caixa da fila, no papel de motorista, enquanto as demais permaneciam no papel de passageiro, sentadas nas demais caixas. Embora tenha 
se desenvolvido na área das estantes, estas não foram utilizadas na brincadeira, pelo menos este uso não foi observado explicita e objetivamente; entretanto, não podemos afirmar que não tenham contribuído para compor o cenário da brincadeira.

Novamente verificamos o papel ativo das crianças, na brincadeira do "Lobo Mau" (15 minutos da última sessão da Fase III), na qual as crianças utilizaram simultaneamente a cabana e a zona circunscrita sem apoio da última fase. A parte inferior da cabana foi direcionada para a zona circunscrita sem apoio, da qual saíam quatro crianças que iam até as proximidades da cabana, gritando como se fossem o "Lobo Mau"; cerca de seis crianças, dentro da cabana, gritavam como assustadas, davam risadinhas e conversavam. A história do Lobo Mau e Os Três Porquinhos estava presente na rotina das crianças, havendo pinturas deste conto infantil nas paredes da sala.

Estes exemplos ilustram a importância dos ambientes infantis fornecerem elementos estruturadores como forma de promover maior desenvolvimento das habilidades infantis, ao possibilitarem às crianças o compartilhamento de conhecimentos já adquiridos e a construção de novos conhecimentos e significados (Carvalho, 1992).

Em relação à análise das categorias comportamentais, verificou-se semelhanças no padrão de ocupação do espaço durante a ocorrência de duas delas, atividade individual e comportamento socialmente dirigido, apesar da primeira ser a categoria com maior freqüência em todas as fases e a segunda, a de menor ocorrência. Em cada uma das duas primeiras fases, elas ocorreram em todas as áreas da sala, sem diferença significativa inter áreas; atividade individual ainda foi a categoria com maior ocorrência em áreas periféricas da sala. Provavelmente, a saliência de atividade individual deva-se ao fato de que, na faixa etária estudada, as crianças estão desenvolvendo suas habilidades sociais e verbais, integrando meios de comunicação verbais e não-verbais, como a imitação (Nadel \& Boudonnière, 1981). Apesar de demonstrarem progressos, durante o terceiro ano de vida há ainda predomínio de interações curtas e simples (Eckerman \& Stein, 1982; Mueller \& Lucas, 1975) e diádicas (Meneghini \& Campos-de-Carvalho, 1997; Stambak \& Verba, 1986).

Quanto às outras categorias, espectador ocorreu significativamente mais na zona do adulto nas duas primeiras fases (na segunda, juntamente com zona circunscrita com apoio), enquanto que interação, nestas duas fases, ocorreu com freqüência significativamente mais elevada na zona circunscrita com apoio, juntamente com a zona do adulto na fase inicial.
$\mathrm{Na}$ Fase II, a alta freqüência de atividade individual observada na zona circunscrita com apoio (embora sem diferença significativa entre áreas), levou-nos a uma comparação com o estudo de Rubiano e Rossetti-Ferreira (1995), onde crianças de 2-3 anos exibiram este comportamento, denominado de atividade isolada, semelhantemente na zona do adulto e na zona circunscrita com apoio, numa sala com a presença de duas zonas circunscritas (ambas com superfície de apoio). As autoras comentam que as crianças se dirigiam para a zona do adulto muitas vezes carregando um único exemplar de um objeto, disputado pelo grupo, o que indicava a busca de proteção da educadora devido a escassez de objetos. A diferença entre os dois trabalhos parece estar no fato de as crianças do presente estudo não precisarem buscar proteção na zona do adulto, dada a presença de maior número de brinquedos, havendo duplicata dos mesmos à disposição das crianças; desta maneira, atividade individual ocorreu mais na zona circunscrita com apoio.

Observou-se que, na fase inicial, as estantes encostadas na parede (áreas sem circunscrição), foram utilizadas bem mais freqüentemente pelas crianças para a ocorrência de atividades desenvolvidas individualmente, como empurrar carrinho, apoiar revistas e folheá-las, etc.. Enquanto que as interações entre crianças ocorreram preferencialmente na zona circunscrita com apoio, delimitada por estantes iguais. Este aspecto, corroborando o estudo de Camposde-Carvalho e Mingorance (1999), aponta o papel de suporte da circunscrição e não apenas da superfície de apoio oferecida pelas estantes e evidencia a relevância de zonas circunscritas para a ocorrência de interações, indo a favor de trabalhos anteriores (Legendre, 1986, 1989, 1999; Rubiano \& Rossetti-Ferreira, 1995).

O maior número de zonas circunscritas na última fase, em comparação à fase inicial, pode ter redirecionado a preferência por áreas na emissão dos comportamentos analisados. Aqueles que exigem maior habilidade social (interação e comportamento socialmente dirigido) ou atenção no outro (espectador), aumentaram da primeira para a última fase, enquanto que atividade individual diminuiu.

Há semelhanças quanto ao local de ocorrência das quatro categorias comportamentais na última fase - preferência significativa por pelo menos uma das três zonas circunscritas. Com exceção do comportamento de espectador, as demais categorias ocorreram com baixa freqüência na zona do adulto nesta fase. Atividade individual e comportamento socialmente dirigido ocorreram com freqüência significativamente maior na zona circunscrita com apoio, enquanto que interação assim ocorreu nas três zonas circunscritas. Provavelmente, as atividades interativas aí desenvolvidas, podem ter chamado a atenção de outras 
crianças, que se aproximavam desta zona, tentando uma abordagem social (comportamento socialmente dirigido) para se integrarem às brincadeiras. Quanto à atividade individual, sua ocorrência foi bastante elevada na zona circunscrita com apoio desde a fase inicial, não tendo sido obtida diferença significativa entre as fases.

Nossos dados apontam que o arranjo espacial com maior número de zonas circunscritas (Fase III), em comparação à presença de apenas uma zona circunscrita (Fase I), favoreceu maior ocorrência de interação, espectador e comportamento socialmente dirigido, e redução de atividade individual. Estes dados evidenciam o papel de suporte das zonas circunscritas para o contato social; embora todas as quatro categorias sejam consideradas interacionais, desde que a análise foi feita em um contexto de grupo, considera-se que atividade individual seja uma categoria com menor envolvimento social. Uma criança, ao se engajar em uma determinada atividade individual, pode estar sendo regulada pelas ações de outra(s), ou suas ações podem vir a regular as ações de outra(s), mesmo que não se observe esta regulação entre os participantes, tal como apontado por Carvalho e colaboradores (1999) e por Branco e colaboradores (1989). Uma próxima análise em outro estudo, poderia buscar indícios para responder esta questão de regulação da atividade individual, bem como verificar em quais áreas do arranjo espacial esta relação ocorre mais freqüentemente.

Quanto à categoria de espectador, pode ser que seja um comportamento antecessor da interação. A criança que observa atentamente, mostra-se interessada no(s) outro(s) e, ao mesmo tempo, pode estar elaborando uma estratégia para abordar outra(s) criança(s), para se integrar numa determinada atividade, podendo resultar numa interação com a(s) mesma(s). No mesmo sentido, um comportamento socialmente dirigido pode ser considerado como uma tentativa de entrar em contato com o outro, que pode ou não culminar em uma interação, dependendo da reação do outro. Entretanto, não nos propusemos aqui a analisar quais comportamentos antecedem uma interação, tal como realizado no estudo de Morais e Rubiano (2000).

Chama atenção a diminuição na freqüência de interação da segunda para a última fase, que pode ter ocorrido porque a cabana, introduzida na sala somente nesta fase, comportava um número restrito de crianças (cerca de seis) em comparação às demais zonas circunscritas - as crianças que ficavam de fora, permaneciam observando o que estava ocorrendo dentro da cabana; o aumento na ocorrência de espectador na última fase é um forte indício deste aspecto. Ademais, como já apontado, nem sempre foi possível analisar no vídeo as atividades das crianças dentro da cabana - isto pode ter colaborado na redução de interações registradas, mas que efetivamente poderiam estar ocorrendo.

O presente estudo aponta que, quanto maior o número de zonas circunscritas, menor são as ocorrências interativas entre crianças na área das educadoras, aumentando em outras áreas da sala. Segundo Howes (1997) e Laike (1997), interações afiliativas tendem a ser mais freqüentes quando ocorrem longe do adulto; isto porque o adulto tende a atrair fortemente a atenção de crianças pequenas (Hartup, 1987). Desta maneira, nossos dados mostram o papel de suporte do maior número de zonas circunscritas para ocorrência de interações longe da área do adulto.

As zonas circunscritas, principalmente aquela com apoio, colaboram para a promoção e manutenção de interações entre coetâneos, pois reduzem a probabilidade de interrupção de atividades por outras crianças e pelas educadoras, o que freqüentemente ocorre em arranjos abertos, oferecendo assim sensação de proteção e privacidade, facilitando a continuidade de suas atividades. Contribuem também na focalização da atenção de uma criança na atividade e comportamento do(s) outro(s), condição necessária para ocorrência de interações mais longas entre coetâneos, especialmente abaixo de 3 anos, como proposto por Camaioni (1980). O presente estudo e os demais de Campos-de-Carvalho e colaboradores apontam que, na presença da zona circunscrita estruturada com estantes, sua superfície de apoio é comumente utilizada pelas crianças para colocar objetos e apoiar o próprio corpo. Rubiano e Rossetti-Ferreira (1995) mostraram que este tipo de zona propicia o desenvolvimento de brincadeiras de fazde-conta, como brincar de casinha, fazer comidinha, comer, beber, deitar o nenê, etc..

A zona circunscrita com superfície de apoio oferece um cenário para brincadeiras, possibilitando a emergência de significações, ações e conhecimentos comuns já vivenciados pelas crianças, relacionados a atividades que, na cultura ocidental, geralmente ocorrem em superfícies elevadas e delimitadas (mesas, cadeiras, estantes, poltronas, etc.). Isto facilita o compartilhamento de atividades no aqui-e-agora, favorecendo a ocorrência de interações mais longas entre crianças, o que propicia, por sua vez, oportunidade para criação de novas brincadeiras e significados.

O cenário da creche é constituído por múltiplos aspectos, físicos e humanos, sendo permeado por uma complexa rede de significações (Rossetti-Ferreira, Amorin \& Silva, 2000). Cada criança componente de um grupo está imersa em inúmeras significações, construídas com base em vários aspectos, tais como sua idade e habilidades, tempo de permanência na creche, mudanças de turma, relações fora da creche, etc., o que influencia o processo interativo com 
outras crianças e adultos no aqui-e-agora. O educador, por sua vez, possui suas próprias significações, permeadas pelo contexto sócio-histórico tanto da instituição (sua ideologia, sua proposta educativa, etc.) como da cultura ou sub-cultura a qual pertence, concebendo educação e desenvolvimento infantil de uma determinada maneira e organizando o espaço físico da creche de acordo com estas significações.

Em suma, o presente trabalho corrobora estudos anteriores (Campos-de-Carvalho \& Mingorance, 1999; Campos-de-Carvalho \& Rossetti-Ferreira, 1993; Legendre, 1986, 1989, 1999; Legendre \& Fontaine, 1991; Meneghini \& Campos-de-Carvalho, 1997), apontando que o arranjo espacial semi-aberto, inclusive com maior número de zonas circunscritas, proporciona maior oportunidade tanto para interações entre crianças, como para ocorrência de atividades individuais e outros comportamentos que podem anteceder um contato social (espectador e comportamento socialmente dirigido), sem a intervenção direta da educadora. Concomitantemente, este tipo de arranjo também favorece a ocorrência de interações com o adulto, em comparação com um arranjo espacial aberto, pois a educadora tem maior disponibilidade para atender as crianças que a procuram, observar suas ações e estabelecer um contato mais individualizado com aquelas que perceba necessitarem de mais atenção, ou desenvolver atividades com um pequeno grupo de crianças. Desta maneira, um arranjo espacial estruturado com zonas circunscritas colabora para uma melhor qualidade do atendimento oferecido às crianças em instituições educacionais.

Sendo o educador o maior responsável pela estruturação e reestruturação contínua dos espaços oferecidos às crianças em ambientes coletivos, seria importante que, em sua formação, tivesse contato com as várias possibilidades de organização de espaços e o que cada uma delas pode proporcionar à criança, desde que esta tenha autonomia para usar e explorar o espaço. Por exemplo, um arranjo espacial com zonas circunscritas de tamanhos variados, pode propiciar múltiplas escolhas de locais e de atividades requerendo diferentes números de participantes; pode ainda oferecer espaços para descanso e atividades mais calmas. Porém, é necessário trabalhar os pressupostos e expectativas que regem as ações do educador, levando-se em conta a sua concepção, bem como a da creche, sobre desenvolvimento infantil e o seu papel na creche. O papel do educador é aquele que deve procurar suprir as necessidades infantis, dirigindo todas as atividades da criança na creche? Ou o educador deve proporcionar mais autonomia à criança para escolher quando, onde, com quem e com quais objetos quer brincar, optando por uma estruturação espacial mais flexível com áreas com e sem circunscrição, supervisionando as interações entre crianças, estando disponível para aquelas que mais precisarem de atenção, bem como para as que o procuram? Deveria o educador sempre centralizar as atividades das crianças, proporcionando para tanto, por exemplo, um local aberto e vazio, encostando todo tipo de mobiliário ao redor do local de atividades infantis, para facilitar sua tarefa?

\section{Referências}

Bonfim, J. A. O. (2002). Arranjos espaciais e ocupação do espaço por crianças de 1-2 e 34 anos em creches. Dissertação de Mestrado não-publicada, Curso de PósGraduação em Psicologia da Faculdade de Filosofia, Ciências e Letras de Ribeirão Preto, Universidade de São Paulo. Ribeirão Preto, SP.

Branco, A. U. A., Carvalho, A. M. A., Pedrosa, M. I. P. C. \& Gil, M. S. C. A. (1989). Fluxo de interações entre crianças numa situação de brinquedo em grupo. Psicologia, 15(11), 13-27.

Bronfenbrenner, U. (1977). Toward an experimental ecology of human development. American Psychologist, 32, 513-531.

Bronfenbrenner, U. (1979). The ecology of human development. Cambridge: Harvard University Press.

Bronfenbrenner, U. (1993). The ecology of cognitive development: Research models and fugitive findings. Em R. H. Wozniack \& K. W. Fisher (Orgs.), Development in context: Acting and thinking in specific environments (pp. 3-44). New Jersey: Erlbaum.

Bronfenbrenner, U. (1995). Developmental ecology through space and time: A future perspective. Em P. Moen, G. H. Elder Jr. \& K. Lüscher (Orgs.), Examining lives in context: Perspectives on the ecology of buman development (pp. 619-647). Washington, DC: APA.

Camaioni, L. (1980). L' interazione tra bambini. Roma: Armando Armando.

Campos-de-Carvalho, M. I. (1993). Psicologia Ambiental: Algumas considerações. Psicologia: Teoria e Pesquisa, 2, 435-447.

Campos-de-Carvalho, M. I., Meneghini, R. \& Mingorance, R. C. (1996). Arranjo espacial e formação de pares entre crianças de 2-3 anos em creches. Psico, 27, 117-137.

Campos-de-Carvalho, M. I. \& Mingorance, R. C. (1999). Zonas circunscritas e ocupação do espaço por crianças pequenas em creche. Revista Interamericana de Psicologia, 33, 67-89.

Campos-de-Carvalho, M. I. \& Padovani, F. H. P. (2000). Agrupamentos preferenciais e não-preferenciais e arranjos espaciais em creches. Estudos de Psicologia, 5, 443-470.

Campos-de-Carvalho, M. I. \& Rossetti Ferreira, M. C. (1993). Importance of spatial arrangements for young children in day care centers. Children's Environments, 10, 19-30.

Carvalho, A. M. A. (1992). Seletividade e vínculo na interação entre crianças. Tese de livre-docência não-publicada, Instituto de Psicologia, Universidade de São Paulo. São Paulo, SP.

Carvalho, A. M. A, Império-Hamburger, A. \& Pedrosa, M. I. (1999). Dados e tirados: Teoria e experiência na pesquisa em Psicologia. Temas em Psicologia da SBP, 7, 205-212.

Dessen, M. A. \& Murta, S. G. (1997). A metodologia observacional na pesquisa em psicologia: Uma visão crítica. Cadernos de Psicologia, 1, 47-60.

Eckerman, C. O. \& Stein, M. R. (1982). The toddler's emerging interactive skills. Em K. H. Rubin \& H. S. Ross (Orgs.), Peer relationship and social skills in childhood (pp. 41-71). New York: Springer-Verlag.

Elali, G. A. (1997). Psicologia e Arquitetura: Em busca do locus interdisciplinar. Estudos de Psicologia, 2, 349-362.

Hartup, W. W. (1987, julho). Relations and growth of social competence. Trabalho apresentado na China Satellite Conference of the International Society for the Study of Behavioural Development, Beijin, China.

Howes, C. (1997). Teacher sensitivity, children's attachment and play with peers. Early Education and Development, 8, 41-49. 
Laike, T. (1997). The impact of day care environments on children's mood and behavior. Scandinavian Journal of Psychology, 38, 209-218.

Ledingham, J. E. \& Chappus, F. T. (1986). Behavioral mappings of children's social interactions: The impact of the play environment. Canadian Journal of Research in Early Childhood Education, 1, 137-148.

Legendre, A. (1986). Effects of spatial arrangements on child/child and child/ caregivers interactions: An ecological experiment in day care centers [Trabalhos completos].Em Sociedade de Psicologia de Ribeirão Preto (Org.), Anais da $16^{a}$ Reunião Anual de Psicologia da Sociedade de Psicologia de Ribeirão Preto (pp. 131-142). Ribeirão Preto, SP: SPRP.

Legendre, A. (1989). Young children's social competences and their use of space in day-care centers. Em B. H. Schneider, G. Attili, J. Nadel \& R. Weissberg (Orgs.), Social competence in developmental perspective (pp. 263276). Holland: Kluwer.

Legendre, A. (1999). Interindividual relationships in groups of young children and susceptibility to an environmental constraint. Environment and Behavior, 31, 463-486.

Legendre, A. \& Fontaine, A. M. (1991). The effects of visual boundaries in two- year- olds' playrooms. Children's Environments Quarterly, 8, 2-16.

Mello, C. O. \& Sperb, T. M. (1997). Para além dos objetos, sem perdê-los de vista. Psicologia: Teoria e Pesquisa, 13, 153-160.

Meneghini, R. \& Campos-de-Carvalho, M. I. (1997). Arranjo espacial e agrupamentos de crianças de 2-3 anos em creches. Revista Brasileira de Crescimento e Desenvolvimento Humano, 7, 63-78.

Moore, G. T. (1987). The physical environment and cognitive development in day care centers. Em C. S. Weinstein \& T. G. David (Orgs.), Spaces for children: The built environment and child development (pp. 41-72). New York: Plenum.

Morais, R. S. \& Rubiano, M. R. B. (2000). Abordagem social entre crianças na creche. Livro de artigos do III Seminário de Pesquisa do Programa de PósGraduação em Psicologia do Departamento de Psicologia e Educação da Faculdade de Filosofia, Ciências e Letras de Ribeirão Preto - USP, 116-122.

Mueller, E. \& Lucas, T. (1975). A developmental analysis of peer interaction among toddlers. Em M. Lewis \& L. A. Rosenblum (Orgs.), Friendship and peer relations (pp. 223-257). New York: John Wiley.

Nadel, J. \& Baudonnière, P. M. (1981). Imitação, modo preponderante de intercâmbio entre pares, durante o terceiro ano de vida. Cadernos de Pesquisa, 39, 26-31.

Oliveira, Z. M. R. de \& Rossetti Ferreira, M. C. (1993). O valor da interação criança-criança em creches no desenvolvimento infantil. Cadernos de Pesquisa, 87, 62-70.

Ormos, S. L., Rubiano, M. R. B. \& Rossetti Ferreira, M. C. (1993). Amostragem de tempo no estudo da organização social de crianças em creche. Psicologia: Teoria e Pesquisa, 1, 173-191.

Pedrosa, M. I. \& Carvalho, A. M. (1995). A interação social e a construção da brincadeira. Cadernos de Pesquisa, 93, 60-65.
Proshansky, H. M., Ittelson, W. H. \& Rivlin, L. (Orgs.) (1970). Environmental Psychology: Man and his physical settings. New York: Holt, Rinehart \& Winston.

Read, M. A., Sugawara, A. I. \& Brandt, J. A. (1999). Impact of space and color in the physical environment on preschool children's cooperative behavior. Environment and Behavior, 31, 413-428.

Rossetti Ferreira, M. C. (1984). O apego e as reações da criança à separação da mãe. Cadernos de Pesquisa, 48, 3-19.

Rossetti Ferreira, M. C., Amorin, K. S. \& Silva, A. P. S. (2000). Uma perspectiva teórico-metodológica para análise do desenvolvimento humano e do processo de investigação. Psicologia: Reflexão e Crítica, 13, 281-293.

Rubiano, M. R. B. \& Rossetti Ferreira, M. C. (1995). Interacción y juegos en las guarderias, el papel de la organización espacial. Revista Latinoamericana de Psycologia, 27, 429-450.

Sommer, B. \& Sommer, R. (1997). A practical guide to behavioral research: Tools and techniques (4 ${ }^{\mathrm{a}} \mathrm{ed}$.). New York: Oxford University Press.

Stambak, M. \& Verba, M. (1986). Organization of social play among todlers: An ecological approach. Em E. C. Mueller \& C. R. Cooper (Orgs.), Process and Outcome in Peer Relationship (pp. 229-247). Orlando: Academic Press.

Stokols, D. (1978). Environmental Psychology. Annual Review of Psychology, 29, 253-295.

Stokols, D. (1995). The paradox of environmental psychology. American Psychologist, 50, 821-837.

Tudge, J., Gray, J. \& Hogan, D. (1997). Ecological perspective in human development: A comparison of Gibson and Bronfenbrenner. Em J. Tudge, M. Shanahan \& J. Valsiner (Orgs.), Comparisons in human development: Understanding time and context (pp. 72-105). New York: Cambridge University Press.

Valsiner, J. (1987). Culture and the development of children's action: A culturalhistorical theory of developmental psychology. New York: Wiley.

Weinstein, C. S. \& David, T. G. (Orgs.) (1987). Spaces for children: The built environment and child development. New York: Plenum.

Weiner, I. B. (1991). Editor's note: Interscorer agreement in Rorschach research. Journal of Personality Assesment, 56, 1.

Wohlwill, J. F. \& Heft, H. (1987). The physical environment and the development of the child. Em D. Stokols \& I. Altman (Orgs.), Handbook of environmental psychology (pp. 281-328). New York: Wiley.

Sobre as autoras

Mara I. Campos-de-Carvalho é Psicóloga, Doutora em Psicologia Experimental pelo Instituto de Psicologia da Universidade de São Paulo, Bolsista do CNPq, docente do Curso de Psicologia e do Programa de Pós-Graduação em Psicologia do Departamento de Psicologia e Educação da Faculdade de Filosofia, Ciências e Letras de Ribeirão Preto-USP (FFCLRP-USP). É membro do CINDEDI-Centro de Investigação de Desenvolvimento Humano e Educação Infantil, realizando pesquisas sobre organização do espaço em instituições pré-escolares.

Renata Meneghini é Psicóloga, Mestre em Psicologia pela FFCLRP-USP e, na época do projeto, era bolsista da FAPESP-Fundação de Amparo à Pesquisa do Estado de São Paulo. Atualmente, é coordenadora pedagógica da área de educação infantil da Secretaria Municipal de Educação de Campos do Jordão (SP) e Professora-tutora do Programa Pedagogia Cidadã (Formação em Nível Superior de Professores de Educação Infantil e de $1^{\mathrm{a}}$ a $4^{\mathrm{a}}$ série - UNESP) em Campos do Jordão (SP). 